\title{
The Impacts of Estrogen and Sesame Oil on the Hippocampal Histomorphologic Changes in Mice
}

\section{Masoomeh Mohammadzadeh, Fahimeh Mazaheri, Fatemeh Anbari, Mohammad Ali Khalili*}

Department of Reproductive Biology, Reproductive Sciences Institute, Shahid Sadoughi University of Medical Sciences, Yazd, Iran

\section{Article Info:}

\section{ABSTRACT}

Introduction: The hippocampus is one of the most important brain regions during adulthood, which has estrogen receptors in both genders. Since, both the estrogen and sesame have neurogenic properties, the objective of the present study was to conduct the impact of estrogen and sesame oil on the hippocampal histomorphologic changes in male mice. Materials and Methods: 20 male mice aged between 35-45 weeks were categorized into four groups: control, (received normal saline), experimental group I (sesame oil only, $10 \mu \mathrm{l} /$ $\mathrm{kg} /$ day), experimental group II (estradiol $1 \mu \mathrm{l} / \mathrm{kg} /$ day), and experimental group III (estradiol $10 \mu \mathrm{l} / \mathrm{kg} /$ day). After a month, brain perfusion was done and the cerebral tissues were fixed for morphological evaluation. Results: There was a significant increase in the thickness of the dentate gyrus (DG), Cornu Ammonis 1 (CA1), and Cornu Ammonis3 (CA3) regions of all experimental groups compared to the control mice. Furthermore, there were a significant increase in the number of the granular cells and the pyramidal cells in the mice treated with sesame oil as well as estradiol at $1 \mu \mathrm{l} / \mathrm{kg} /$ day. The mean number of necrosis-like cells in the CA1 and CA3 regions in the groups treated with sesame oil and estradiol at $1 \mu \mathrm{l} / \mathrm{kg} / \mathrm{day}$ was significantly lower the mice treated with $10 \mu \mathrm{l} / \mathrm{kg} /$ day estradiol. Conclusion: Our data indicate that estrogen and sesame oil maintain the thickness of the CA1, CA3 and DG regions and enhance the number of the granular cells and the pyramidal cells in the hippocampal DG and CA1 areas, respectively. These findings suggest the modulatory effects of estrogen and sesame on the hippocampal function.

\section{Key words:}

1. Estradiol

2. Sesame Oil

3. Hippocampus

4. Mice

*Corresponding Author: Mohammad Ali Khalili

E-mail: Khalili59@hotmail.com 


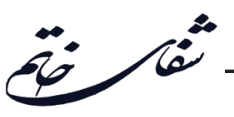

\section{اثرات استرورن و روغن كنجد بر تغييرات بافتشناسى هييوكامٍ در موشهاى سورى}

\section{معصومه محمد زاده، فهيمه مظاهرى، فاطمه انبارى، محمدعلى خليلى"}

كَروه بيولوزى توليد مثل، يزوهشكده علوم توليد مثل، دانشكاه علوم يزشكى شهيد صدوقى، يزد، ايران

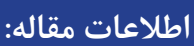

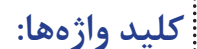

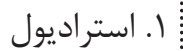

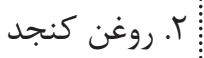

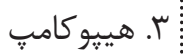

:

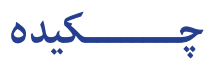

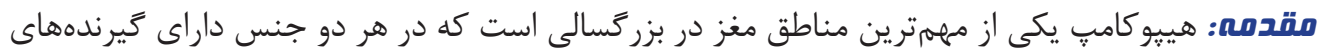

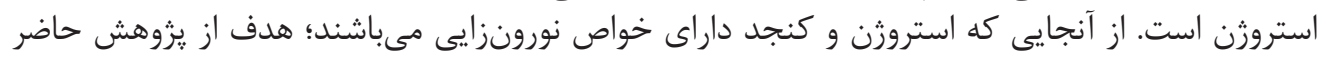

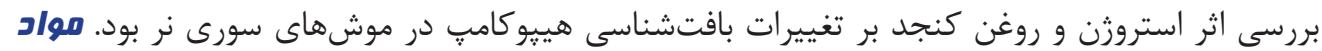

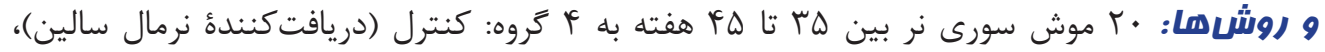

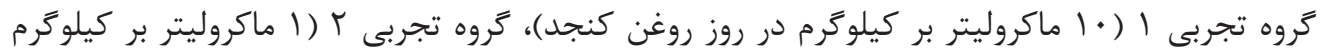

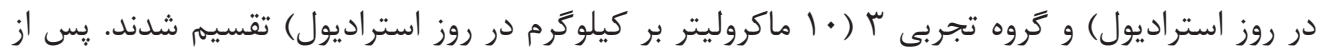

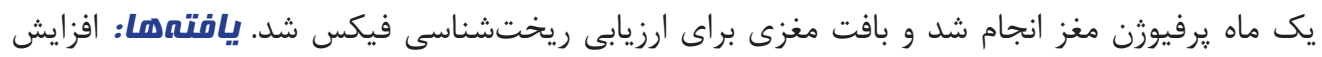

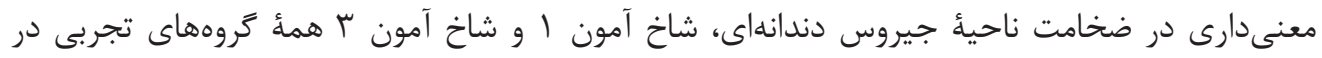

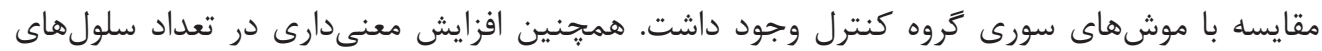

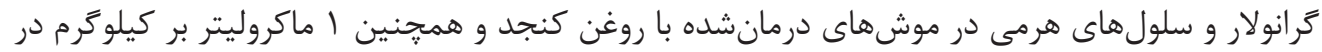

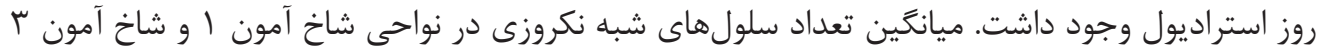

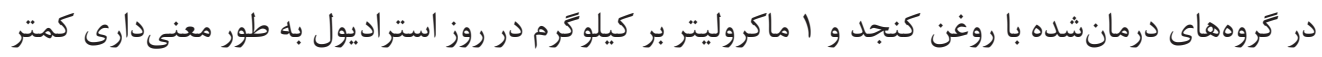

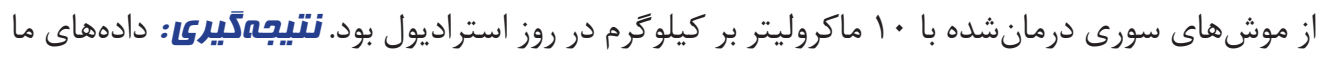

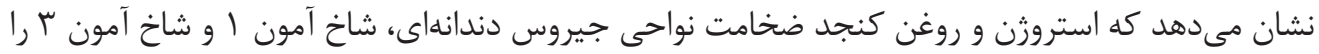

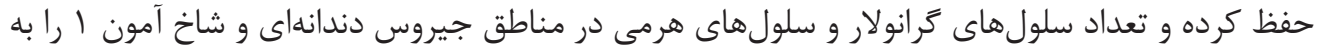

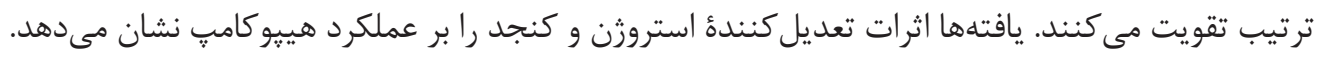

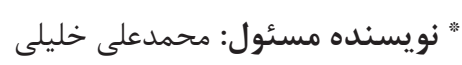

آدرس الكترونيكى: Khalili59@hotmail.com 


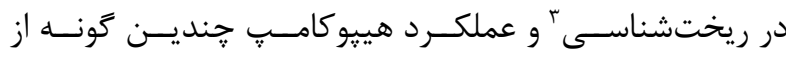

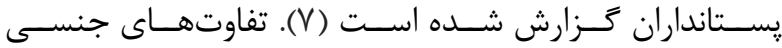

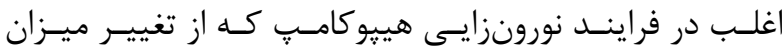

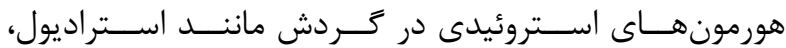

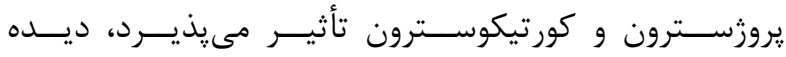

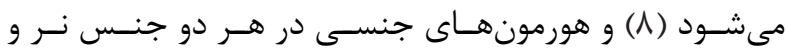

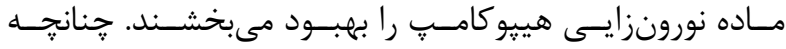

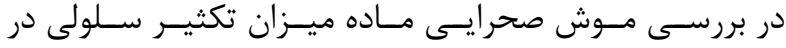

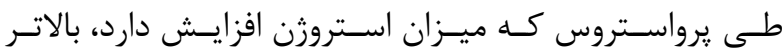

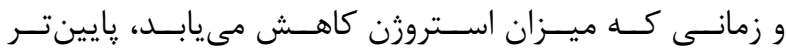

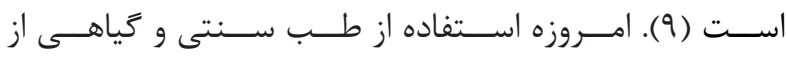

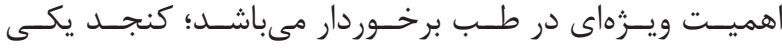

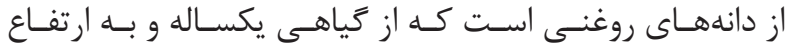

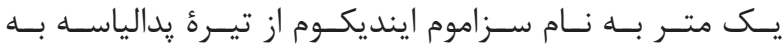

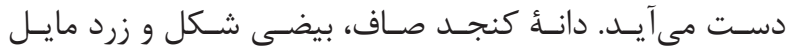

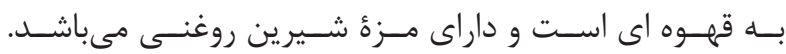

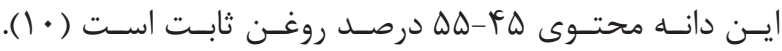

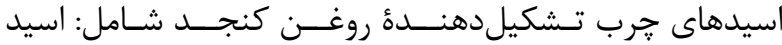

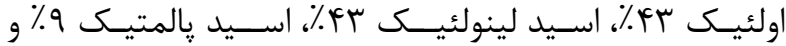

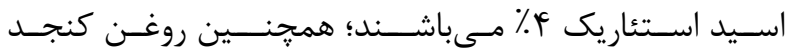

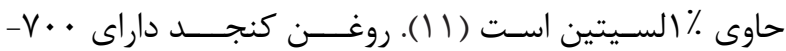

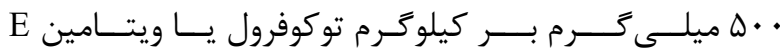

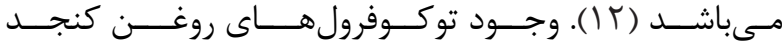

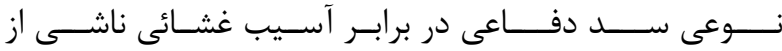

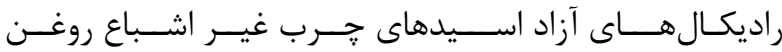

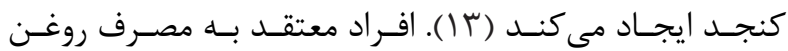

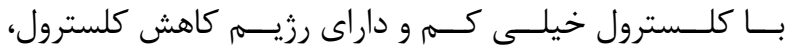

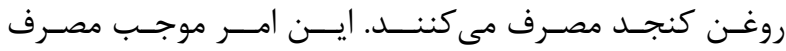

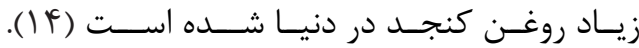

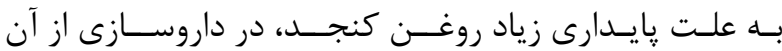

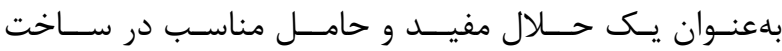

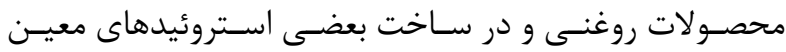

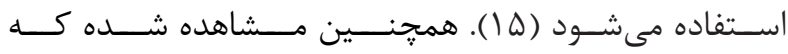

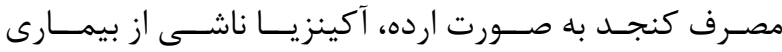

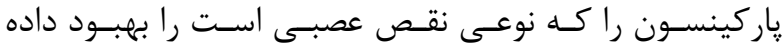

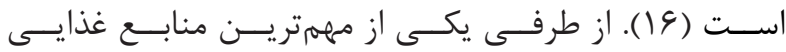

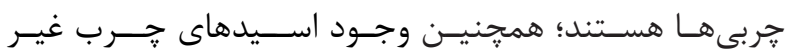

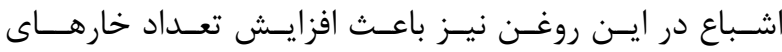

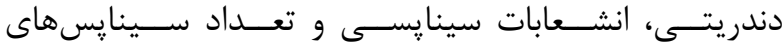

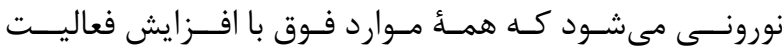

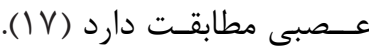

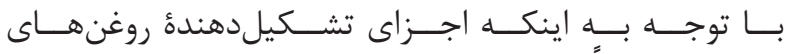

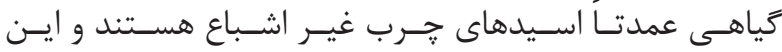

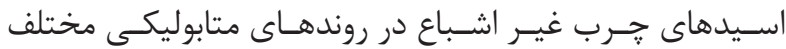

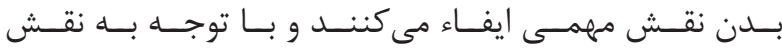

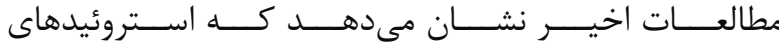

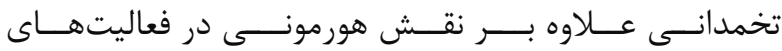

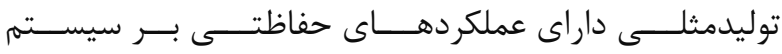

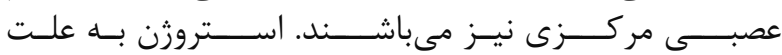

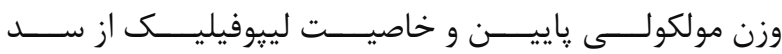

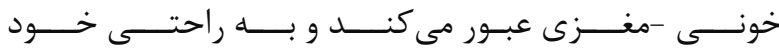

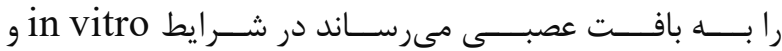
ثابـت شـــ in vivo

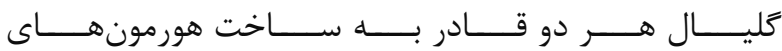

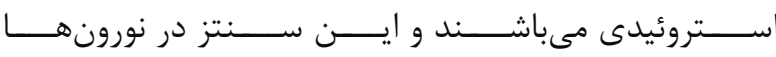

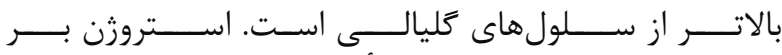

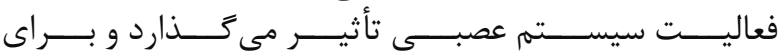

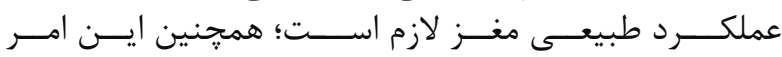

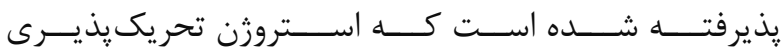

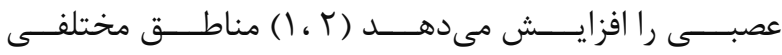

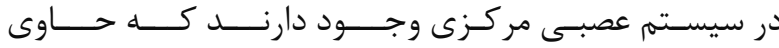

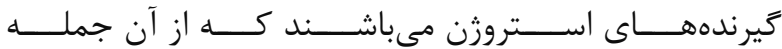

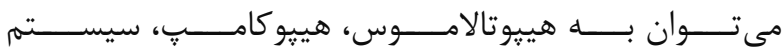

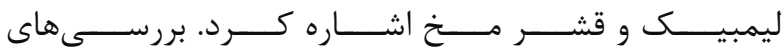

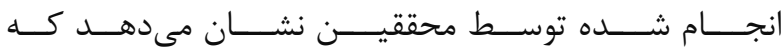

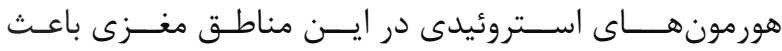

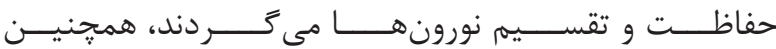

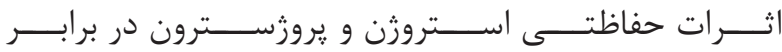

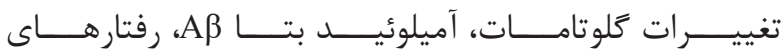

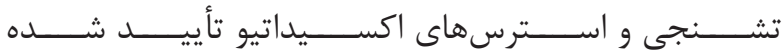

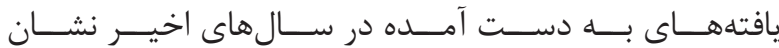

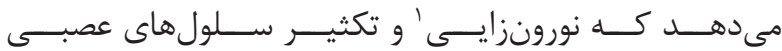

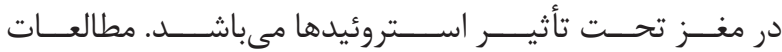

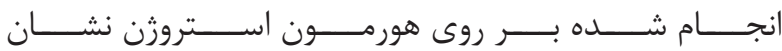

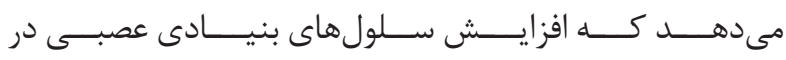

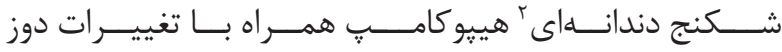

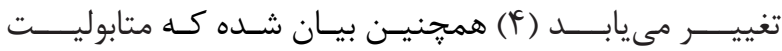

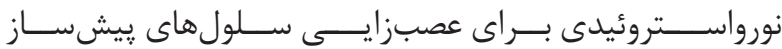

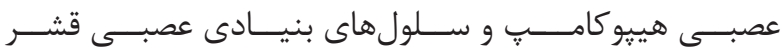

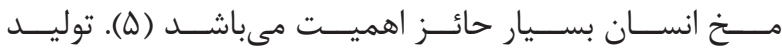

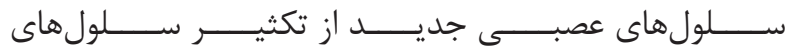

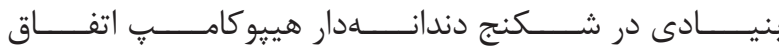

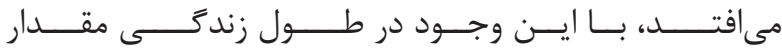

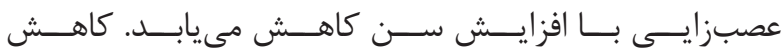

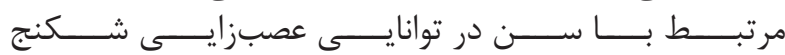

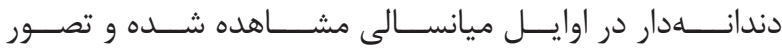

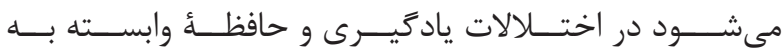

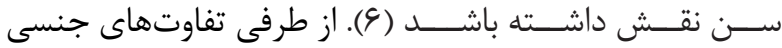




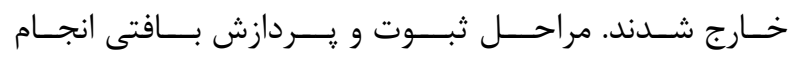

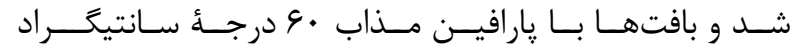

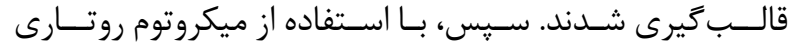

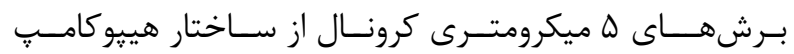

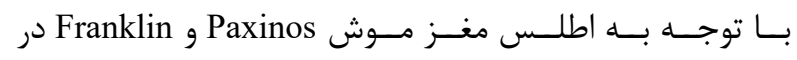

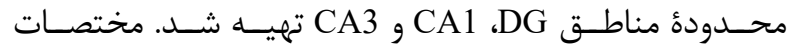

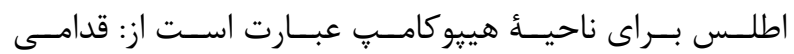

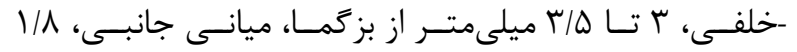

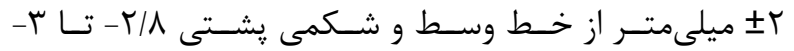

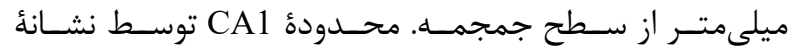

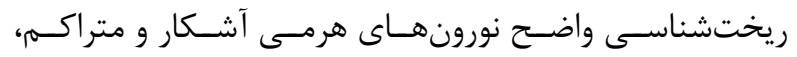

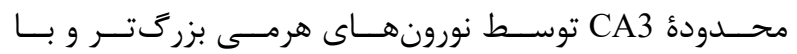

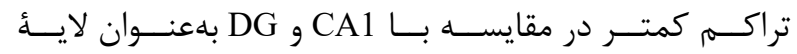

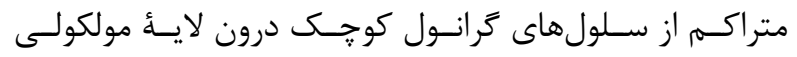

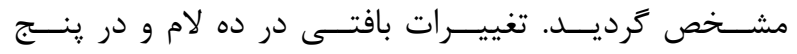

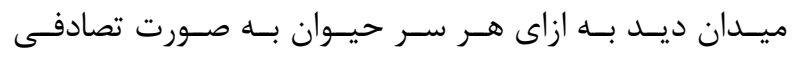

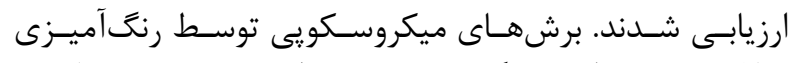

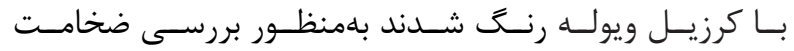

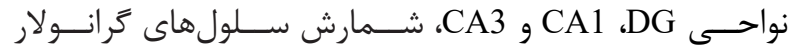

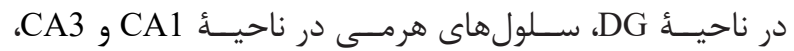

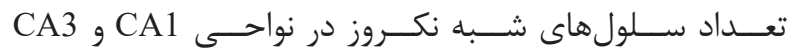

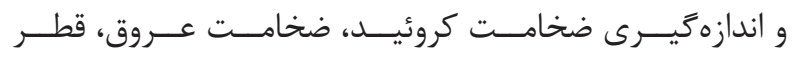

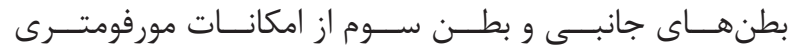

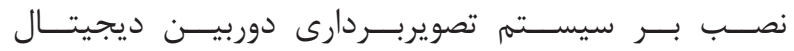
Micrometrics SE و نرمافـــــ (Nikon, DXM120, USA)

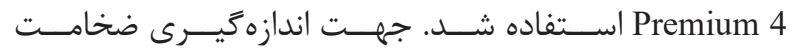

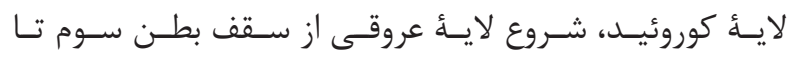

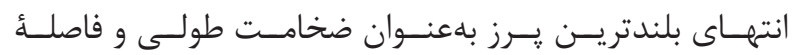

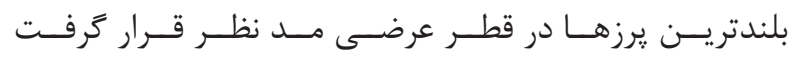

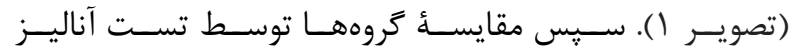

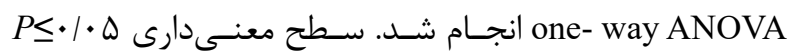

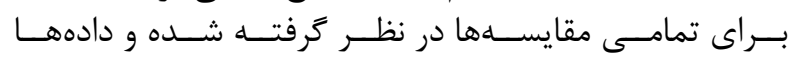

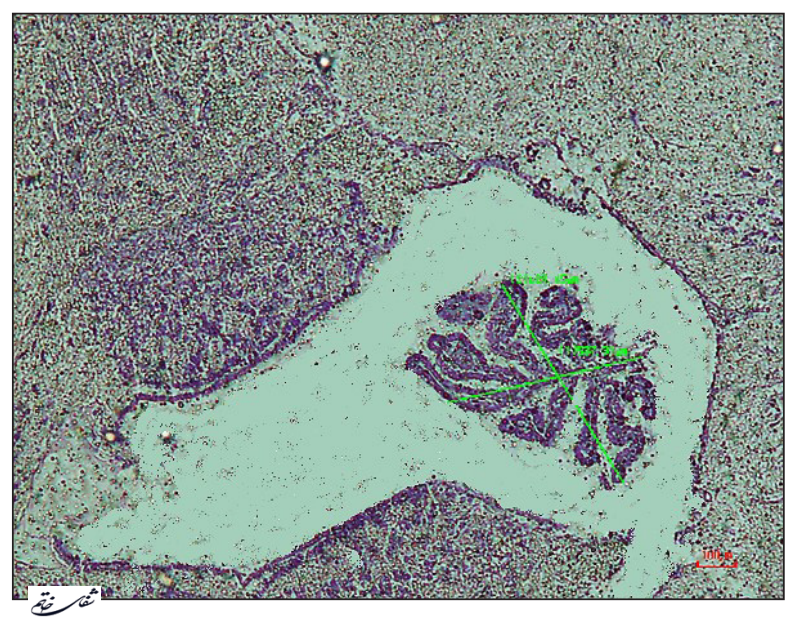

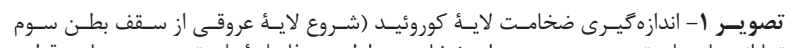

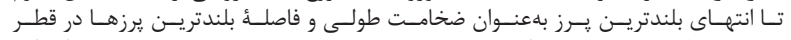

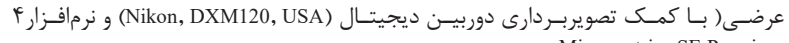
Micrometrics SE Premium

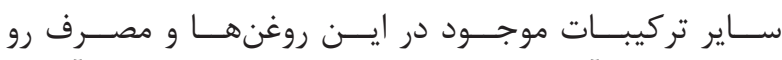

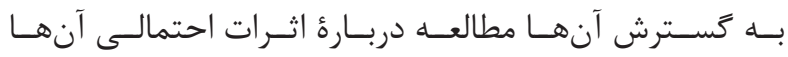

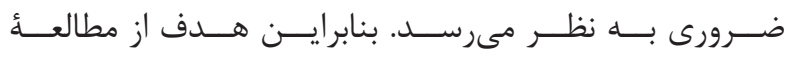

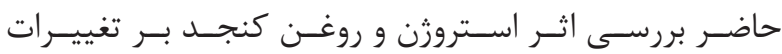

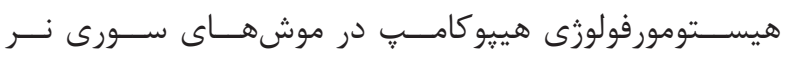

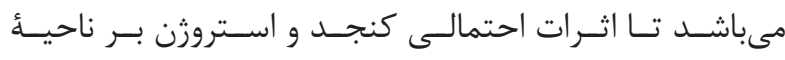

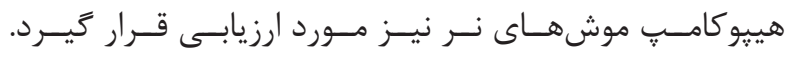

مواد و روشها

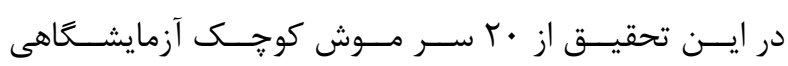

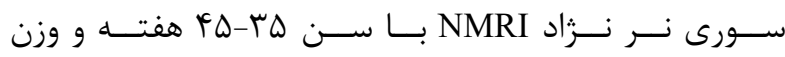

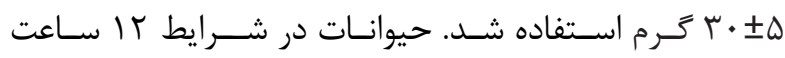

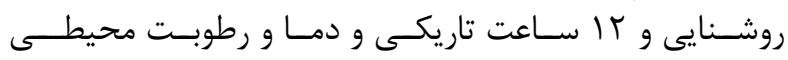

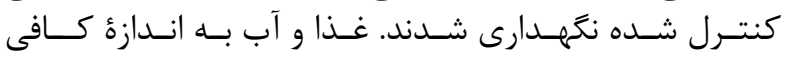

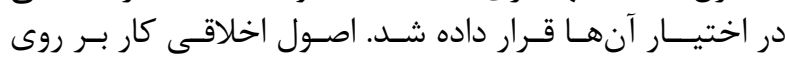

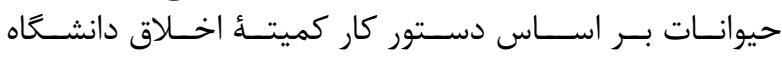

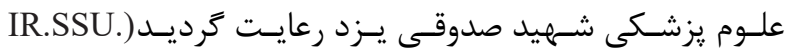
.(RSI.REC.1394.5

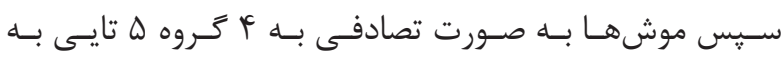

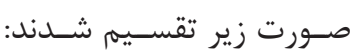

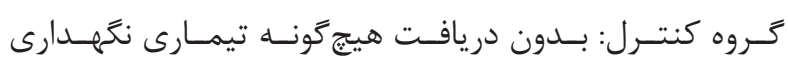

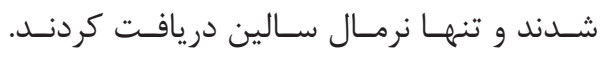

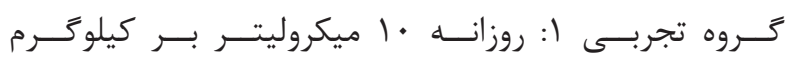

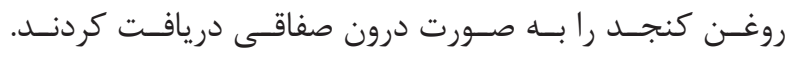

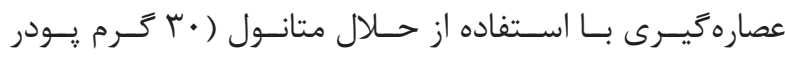

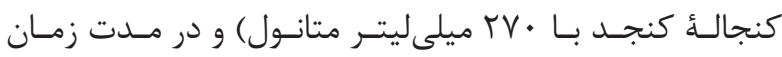

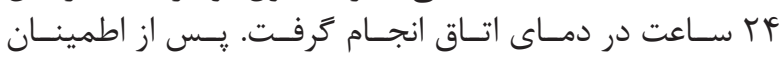

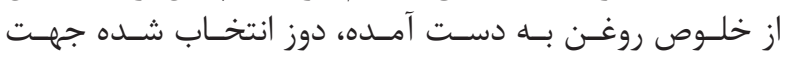

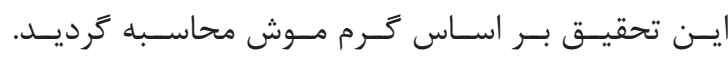

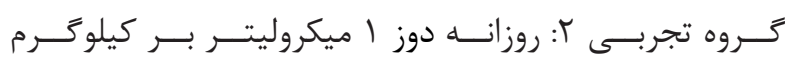

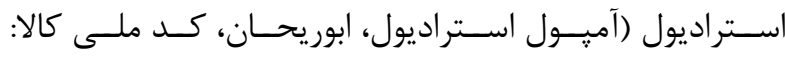

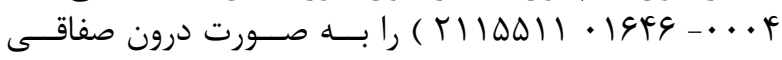

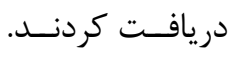

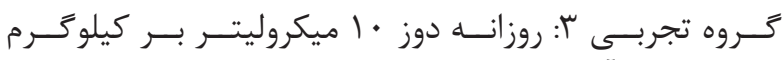

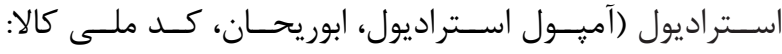

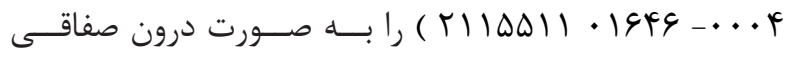

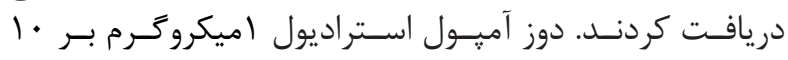

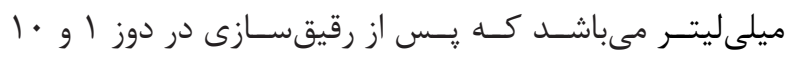

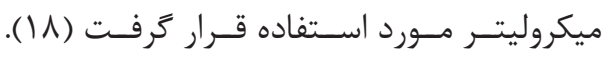

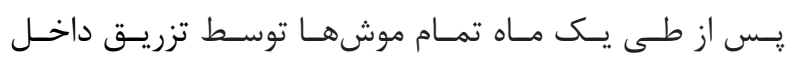

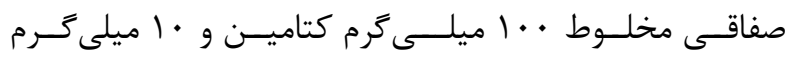

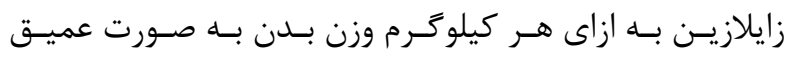

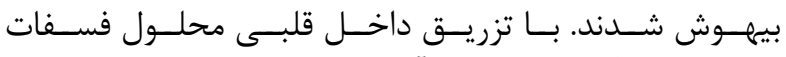

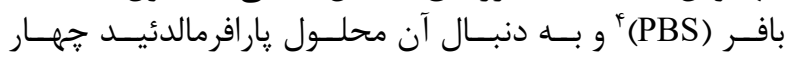

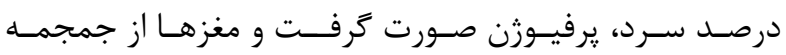

${ }^{4}$ Phosphate buffered saline 


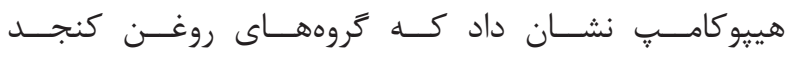

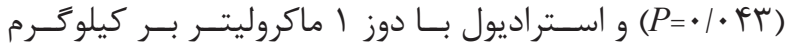

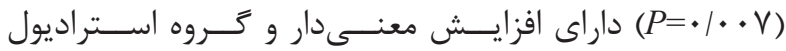

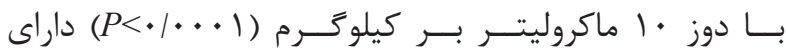

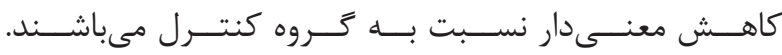

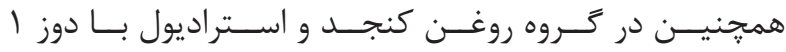

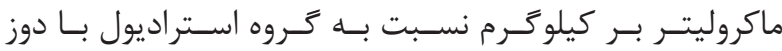

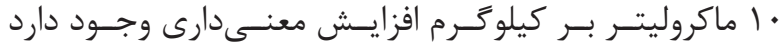

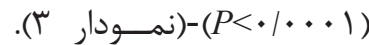

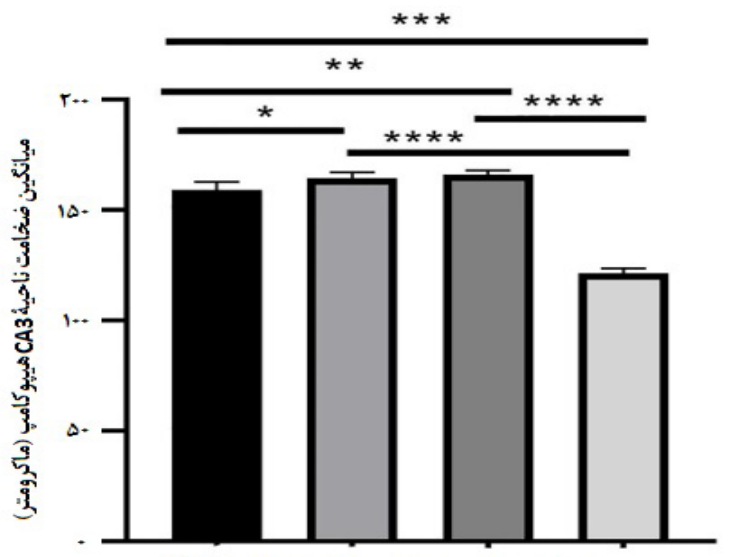

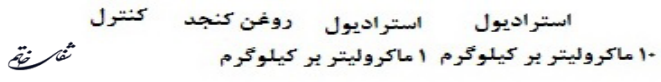

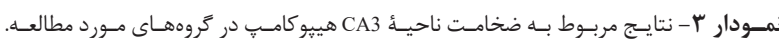

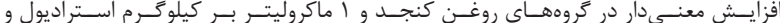

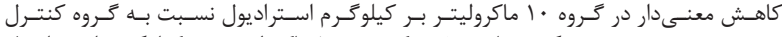

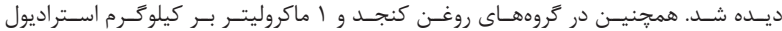

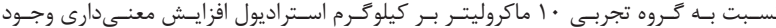

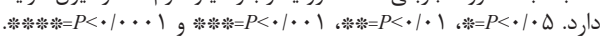

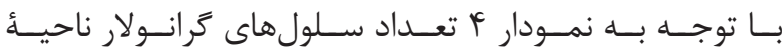

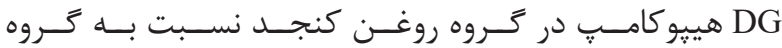

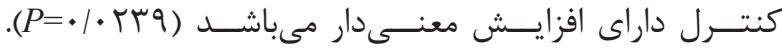

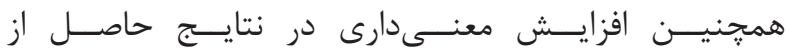

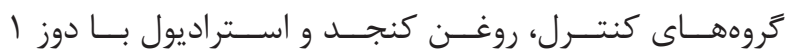

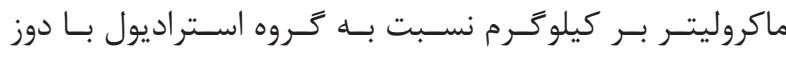

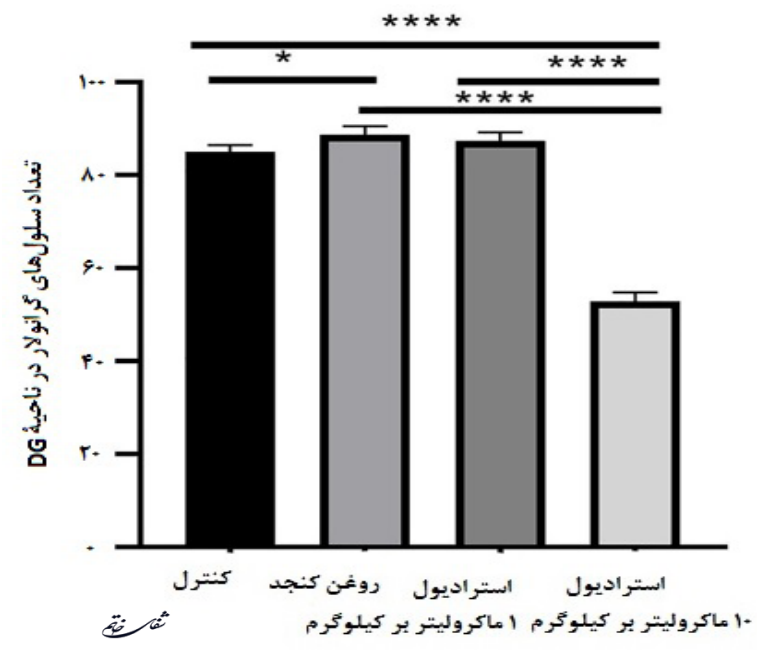

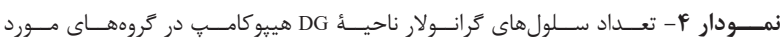

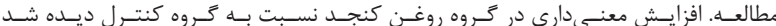

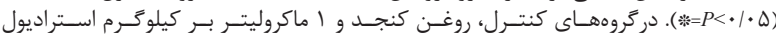

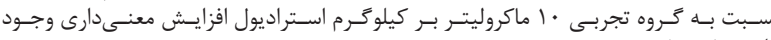
(د)
بــه صـورت ميانگيـن \pm خطــاى معيــار بيــان شـدند.

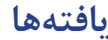

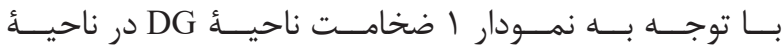

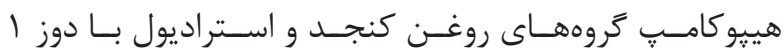

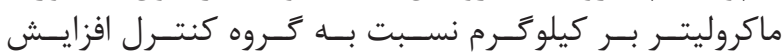

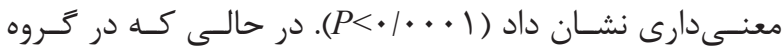

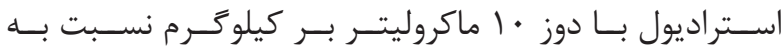

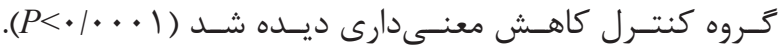

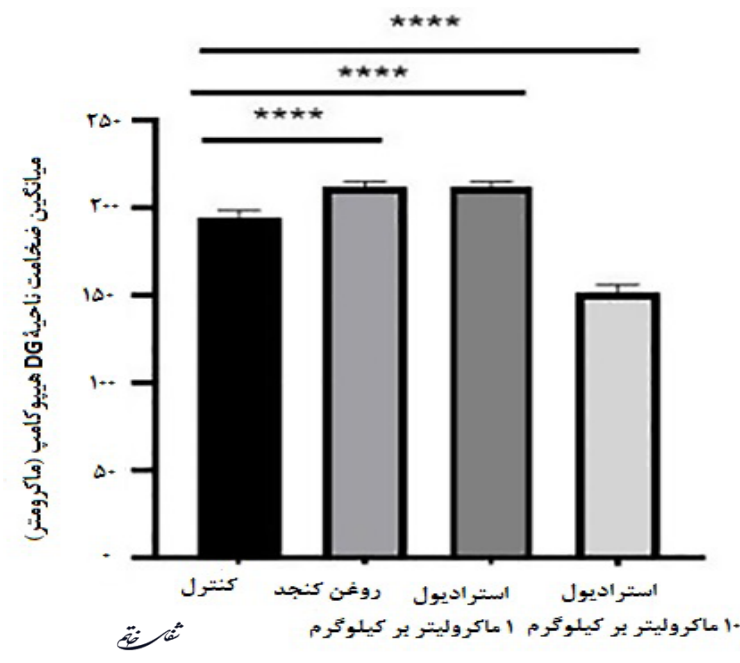

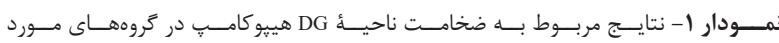

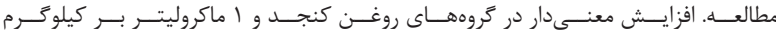

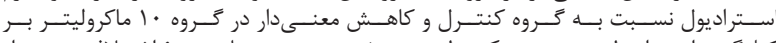

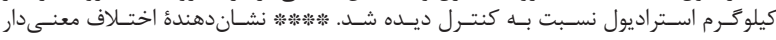
(P<•/ $)$

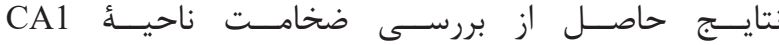

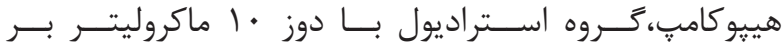

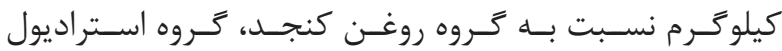

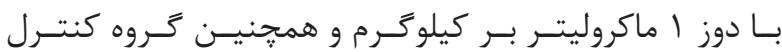

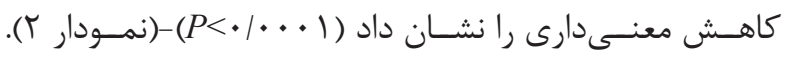

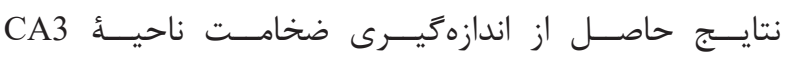

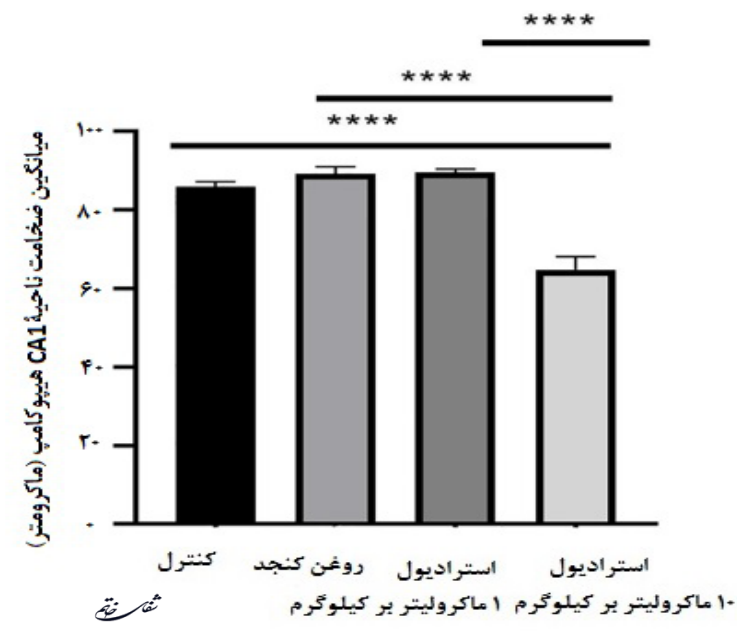

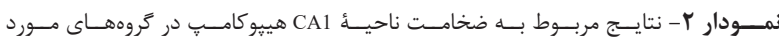

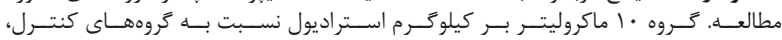

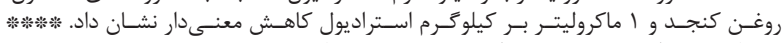

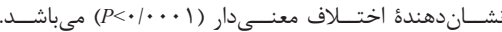




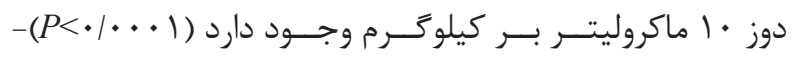

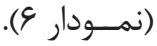

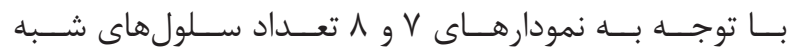

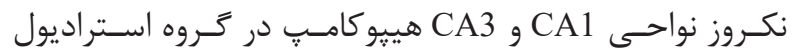

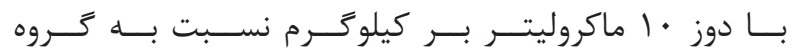

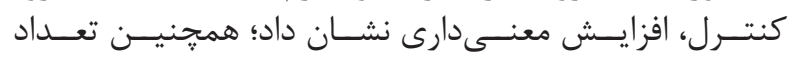

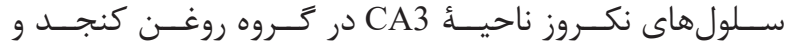

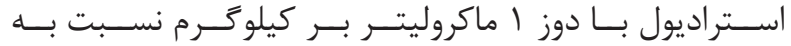

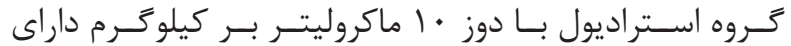

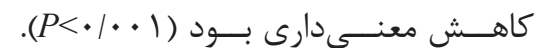

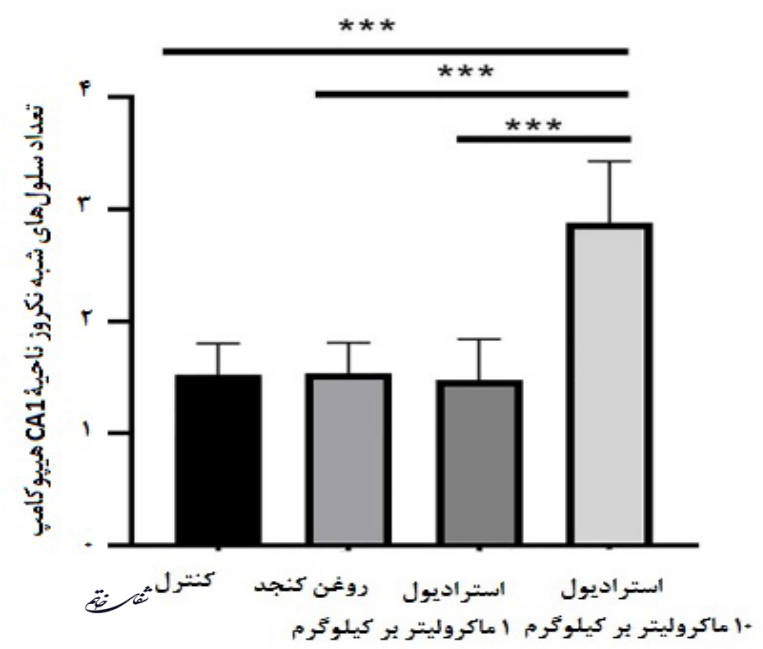

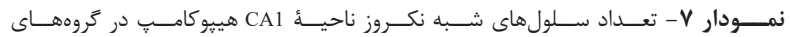

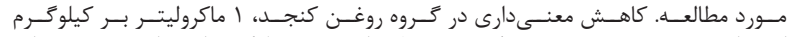

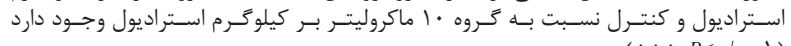

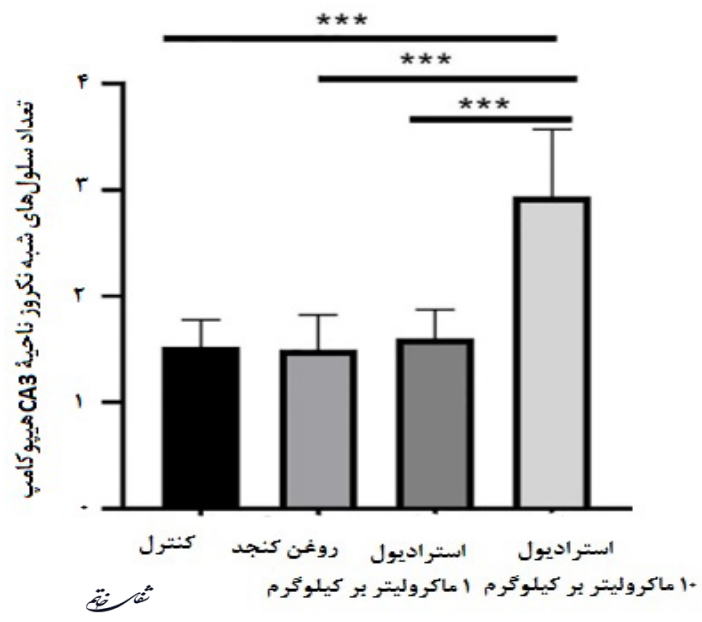

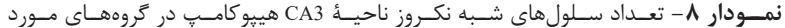

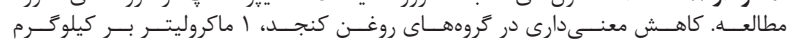

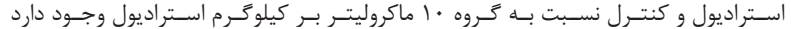

$($ (***** $=P<\cdot /, \cdot 1)$

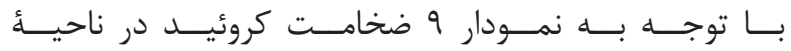

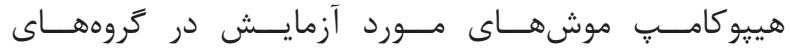

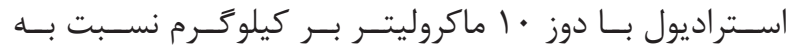

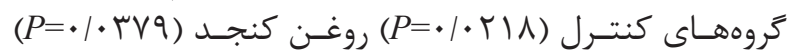

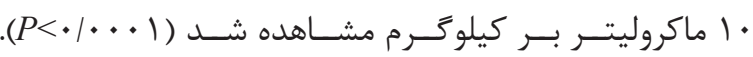

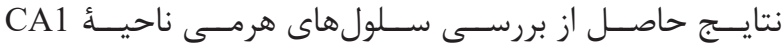

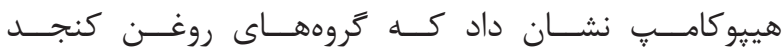

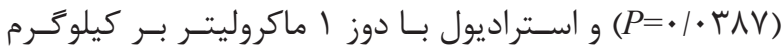
(P=•/ r TV )

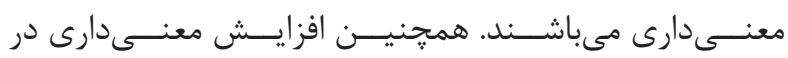

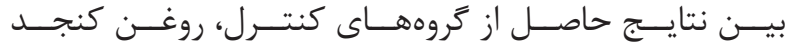

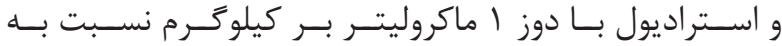

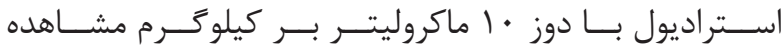

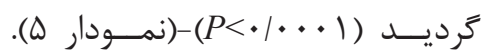

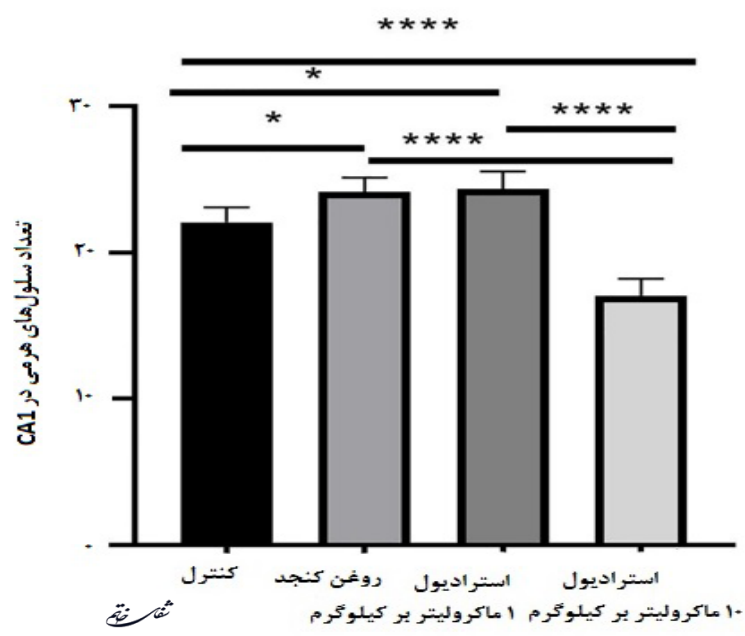

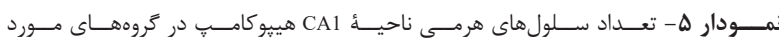

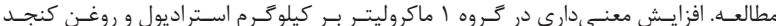

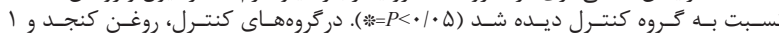

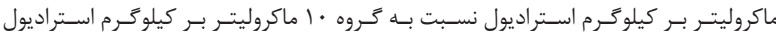

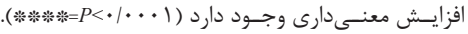

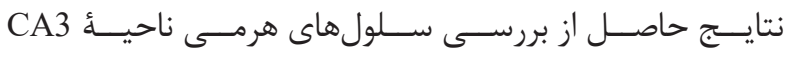

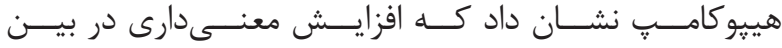

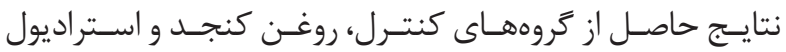

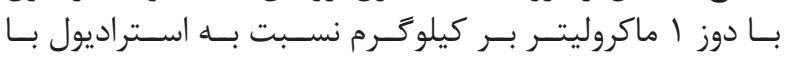

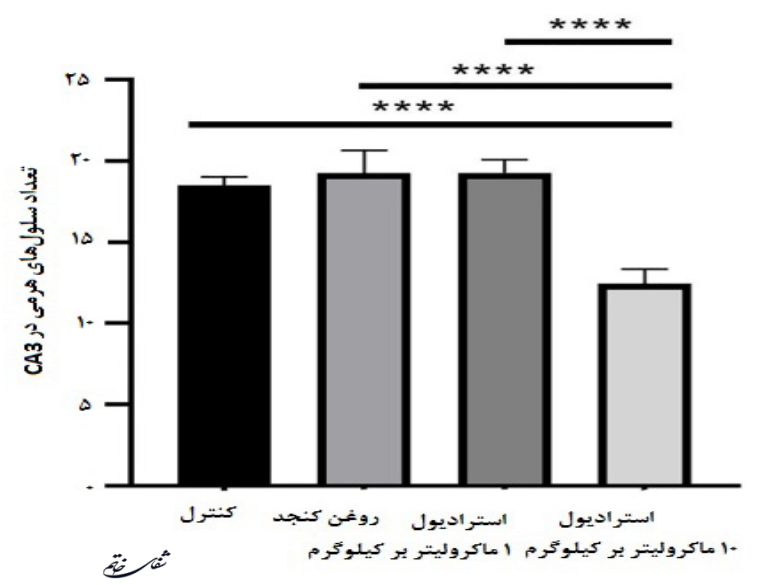

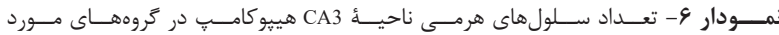

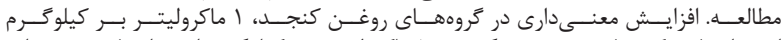

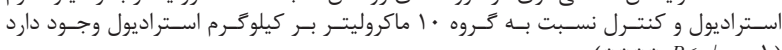




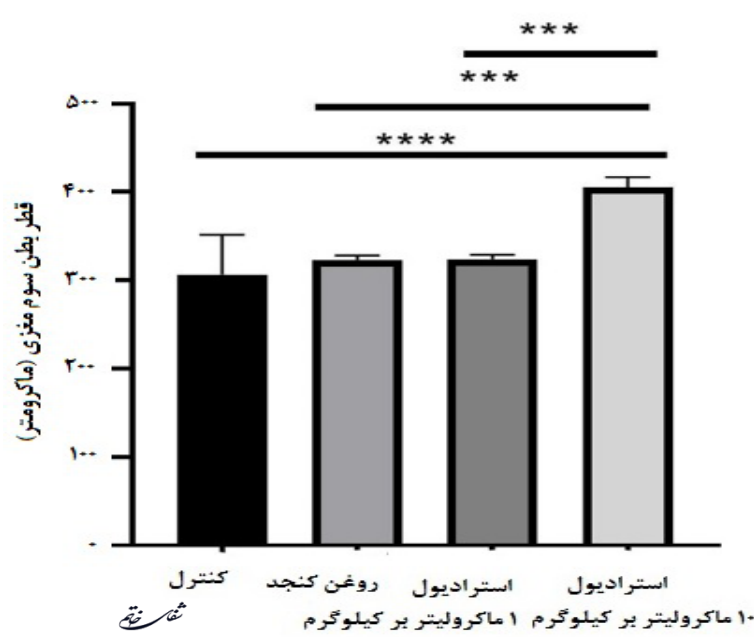

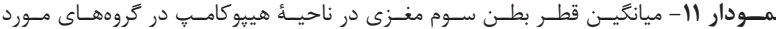

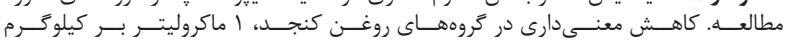

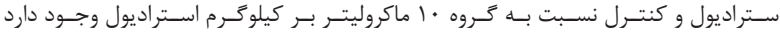

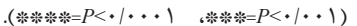

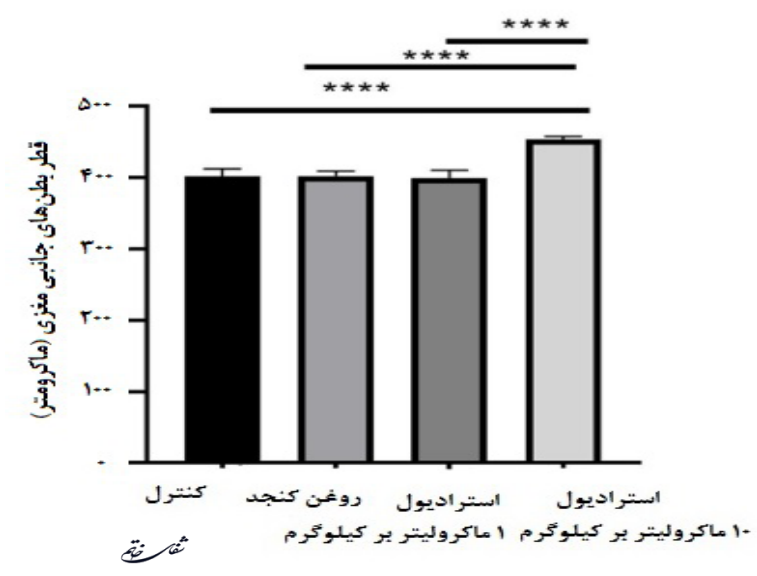

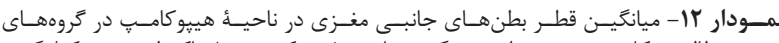

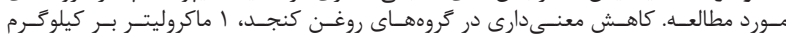

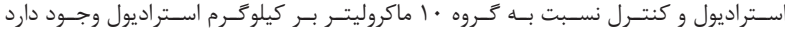

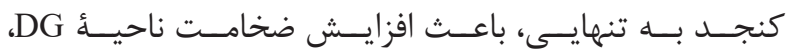

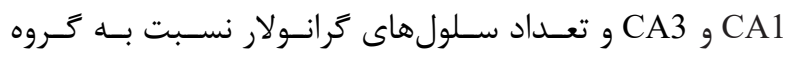

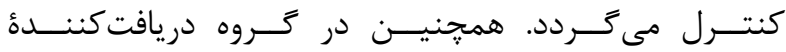

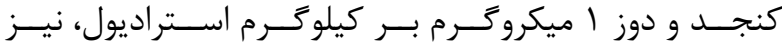

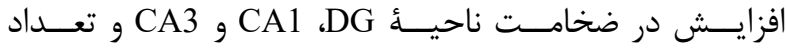

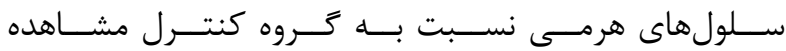

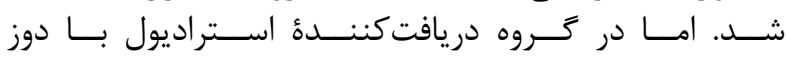

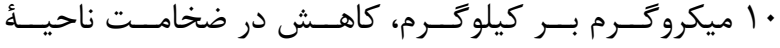

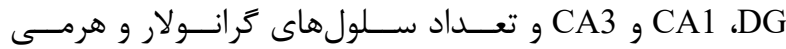

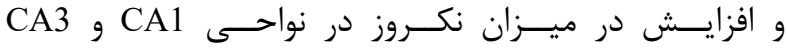

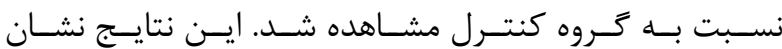

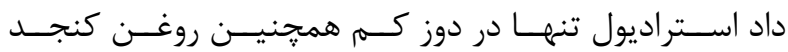

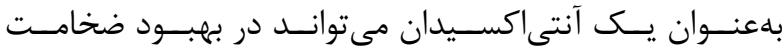

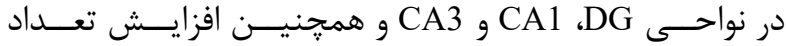

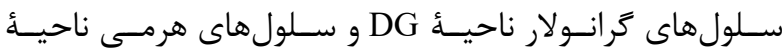

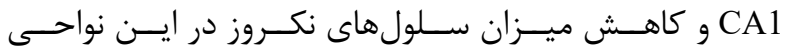

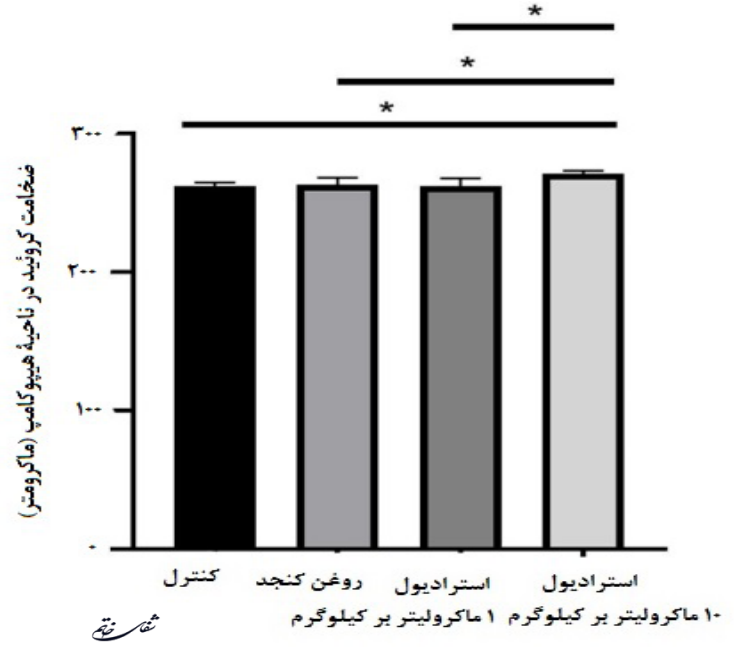

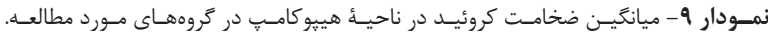

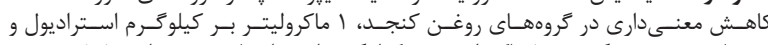

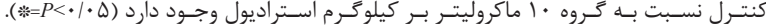

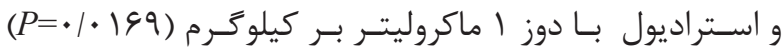

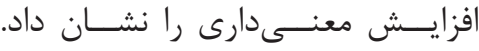
بـا توجــه بـهـ نمـودار • ا ضخامست عـروق در ناحيـهُ هييو كامي

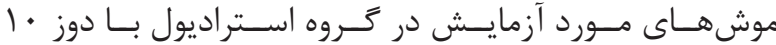

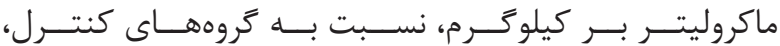

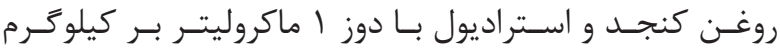

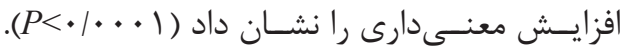

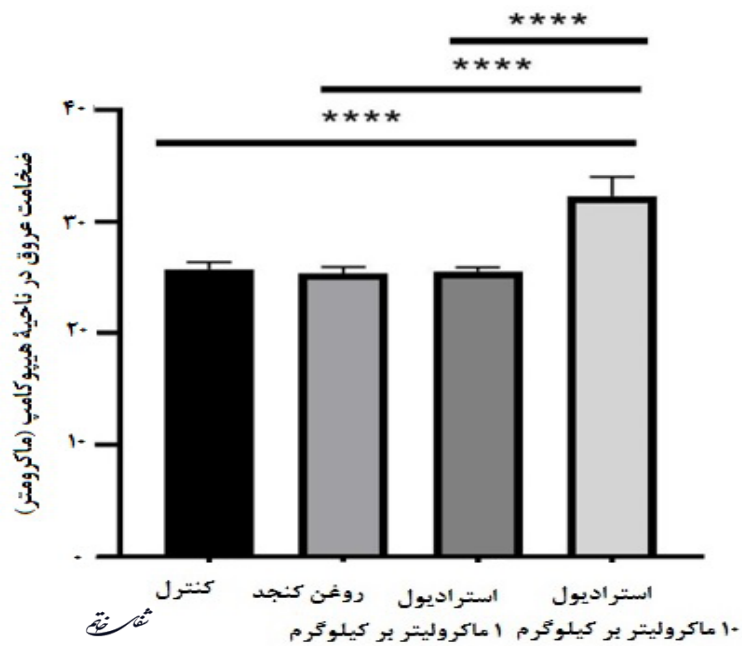

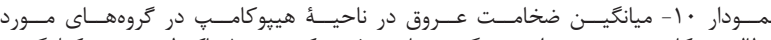

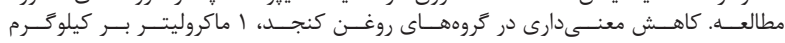

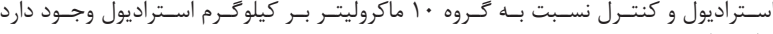

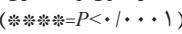

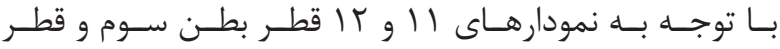

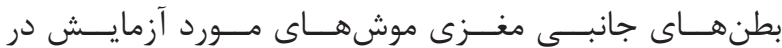

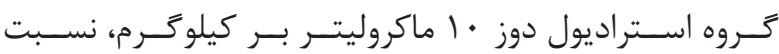

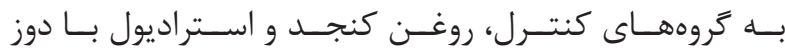

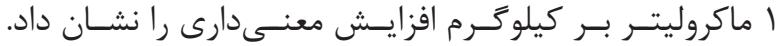

$$
\text { بحث و نتيجه كيرى }
$$

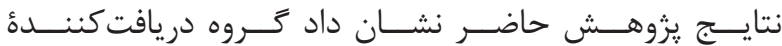




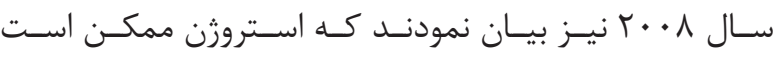

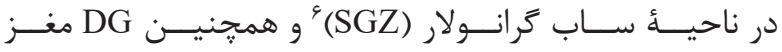

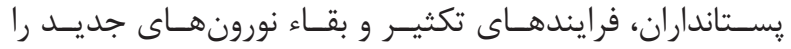

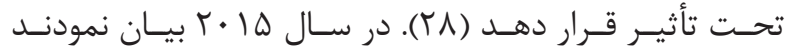

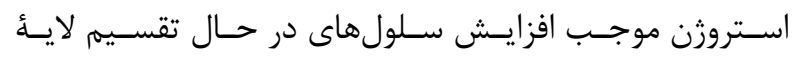

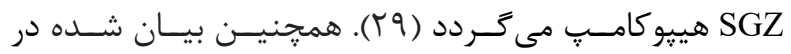

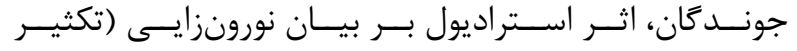

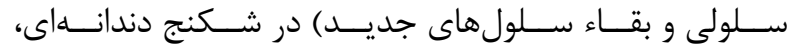

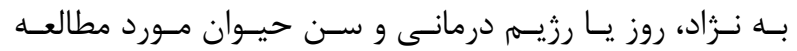

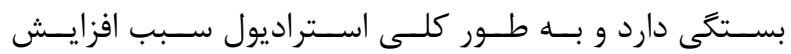

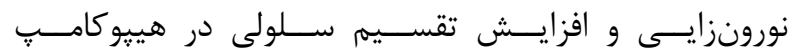

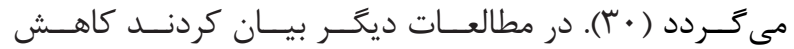

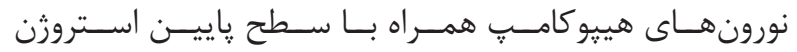

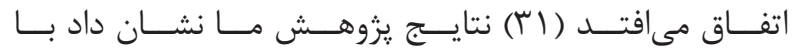

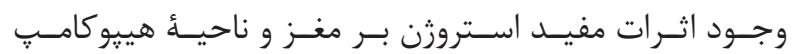

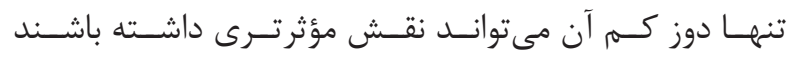

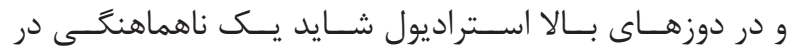

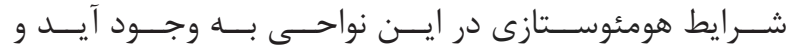

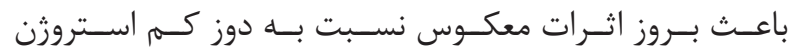

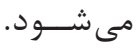

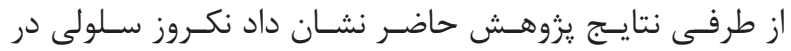

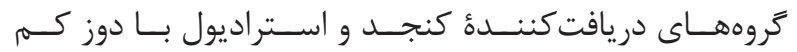

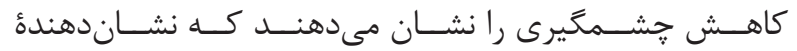

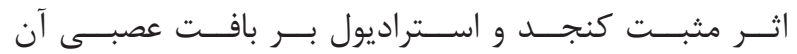

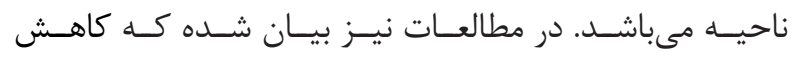

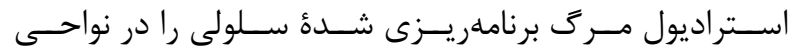

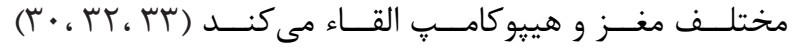

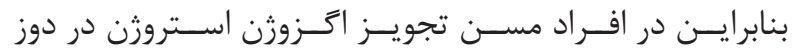

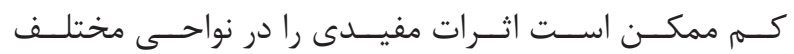

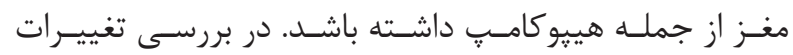

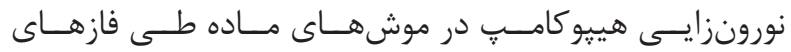

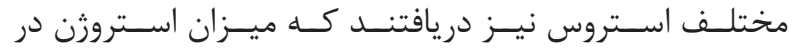

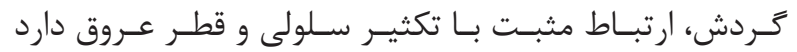

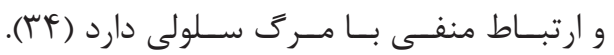

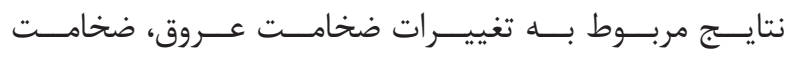

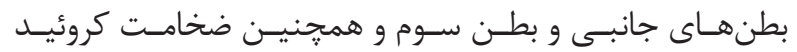

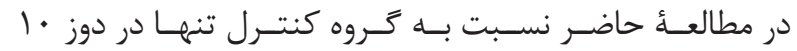

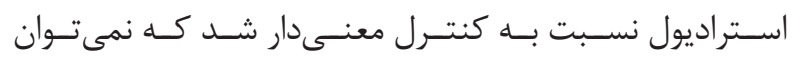

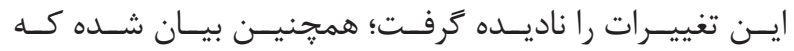

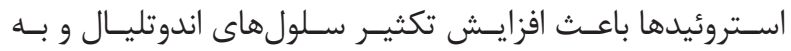

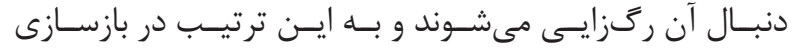

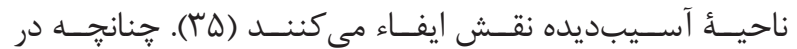

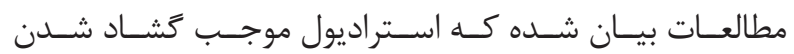

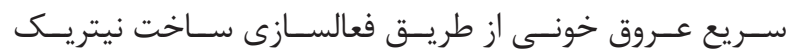

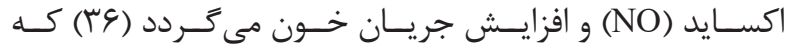

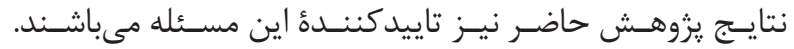

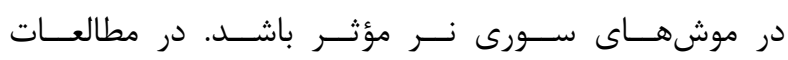

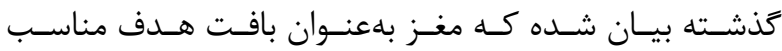

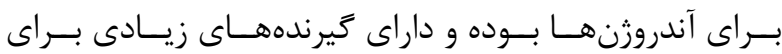

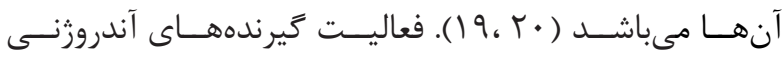

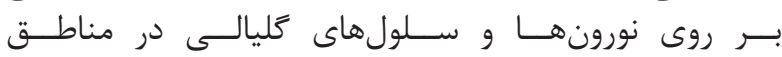

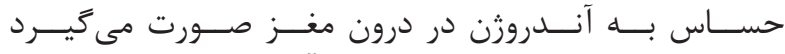

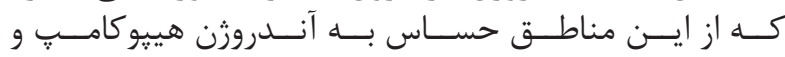

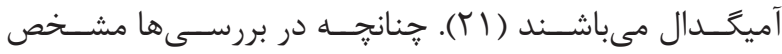

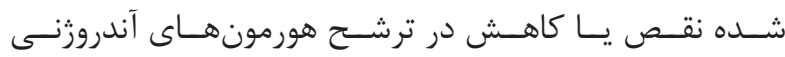

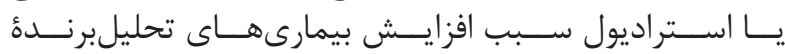

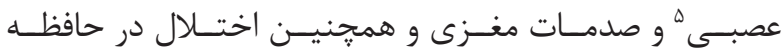

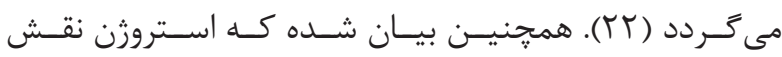

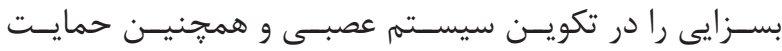

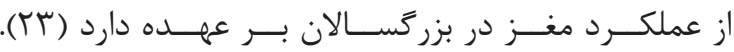

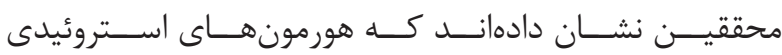

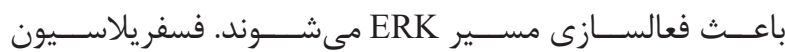

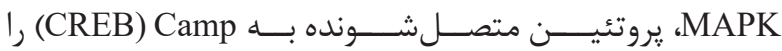

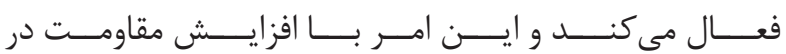

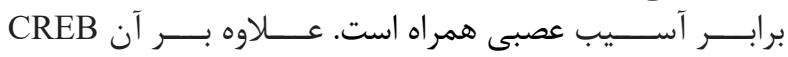

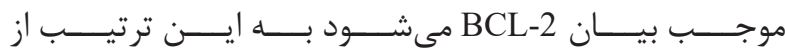

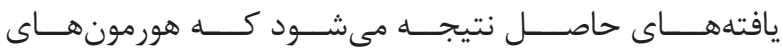

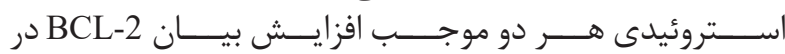

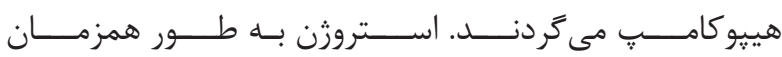

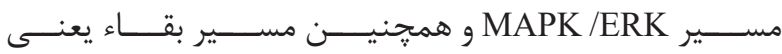

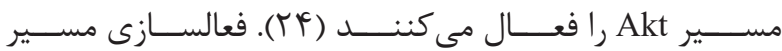

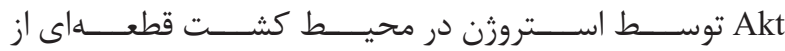

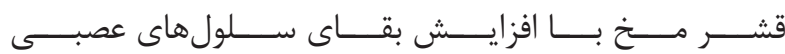

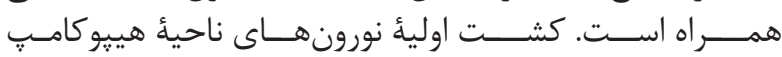

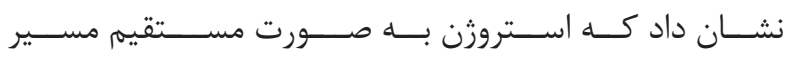

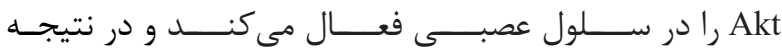

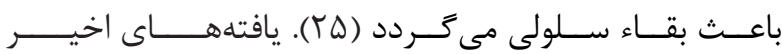

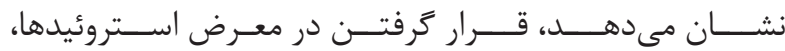

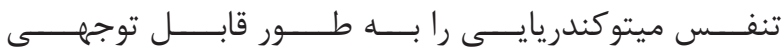

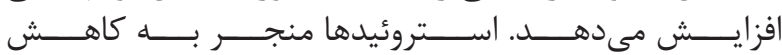

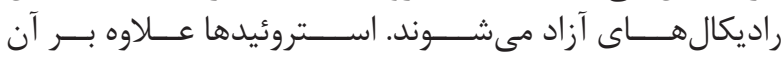

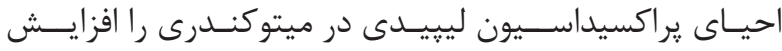

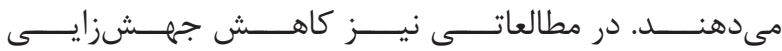

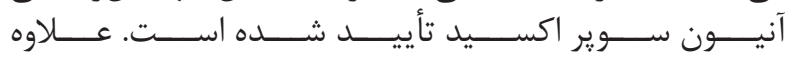

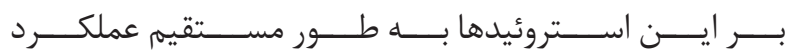

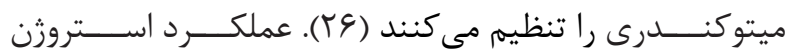

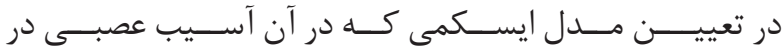

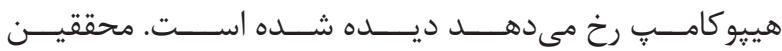

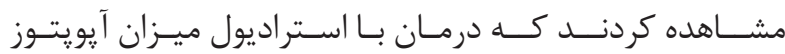

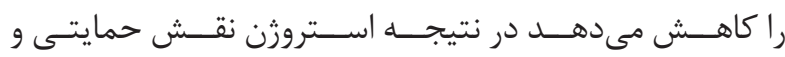

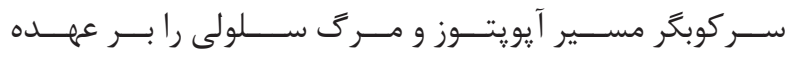

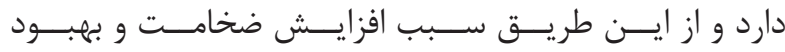

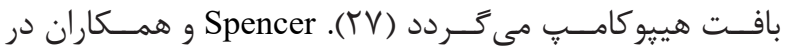




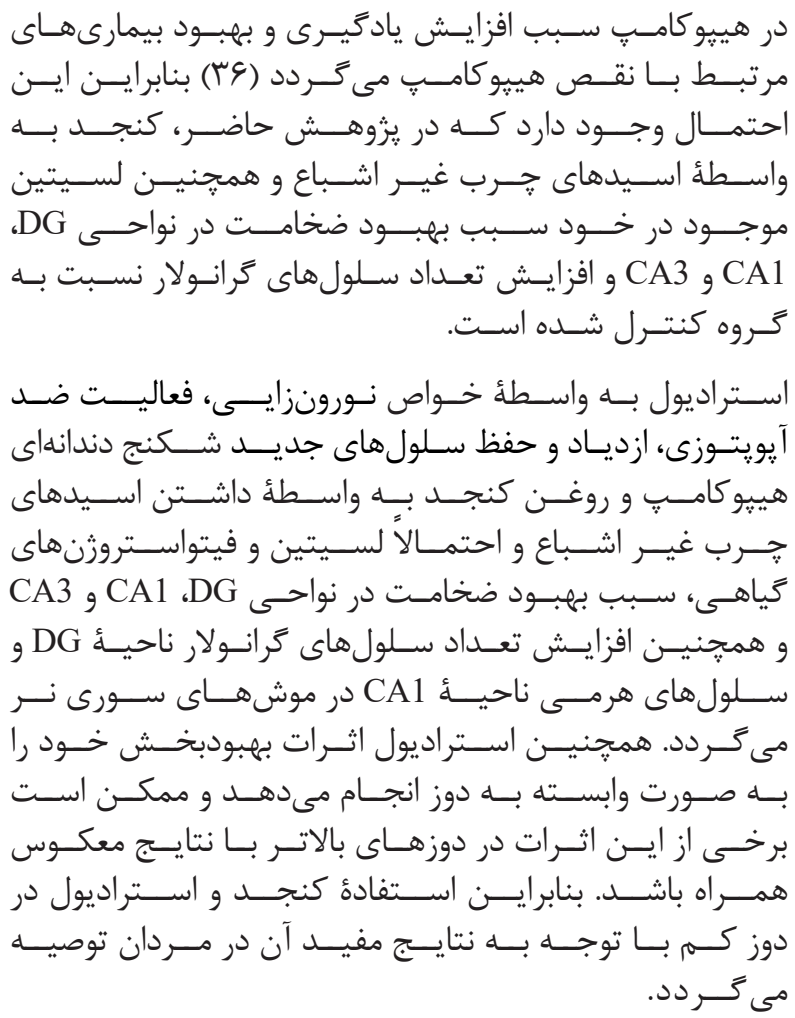

1. Beyer C. Gonadal steroid hormones as therapeutic tools for brain trauma: The time is ripe for more courageous clinical trials to get into emergency medicine. J Steroid Biochem Mol Biol. 2015; 146: 1-2.

2.Gaignard P, Savouroux S, Liere P, Pianos A, Thérond P, Schumacher M, et al. Effect of sex differences on brain mitochondrial function and its suppression by ovariectomy and in aged mice. Endocrinology. 2015; 156(8): 2893-904.

3. Lammerding L, Slowik A, Johann S, Beyer C, Zendedel A. Poststroke inflammasome expression and regulation in the peri-infarct area by gonadal steroids after transient focal ischemia in the rat brain. Neuroendocrinology. 2016; 103(5): 460-75.

4. Diep CH, Daniel AR, Mauro LJ, Knutson TP, Lange CA. Progesterone action in breast, uterine, and ovarian cancers. J Mol Endocrinol. 2015; 54(2): R31-R53.

5. Gonçalves JT, Schafer ST, Gage FH. Adult neurogenesis in the hippocampus: from stem cells to behavior. Cell. 2016; 167(4): 897-914.

6. Rao MS, Hattiangady B, Abdel-Rahman A, Stanley DP, Shetty AK. Newly born cells in the ageing dentate gyrus display normal migration, survival and neuronal fate choice but endure retarded early maturation. Eur J Neurosci. 2005; 21(2): 464-76.

7. Zarate S, Jaita G, Zaldivar V, Radl D, Eijo G, Ferraris

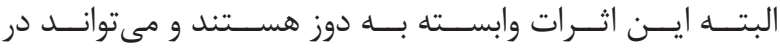

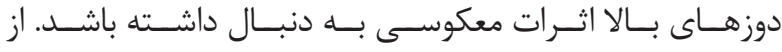

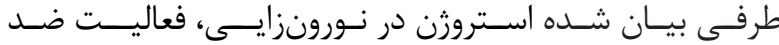

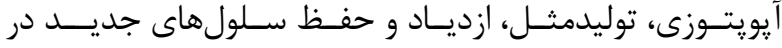

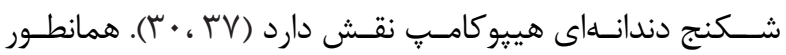

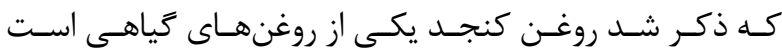

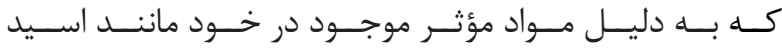

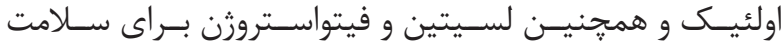

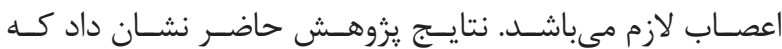

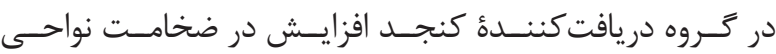

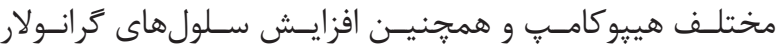

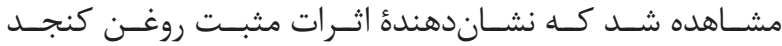

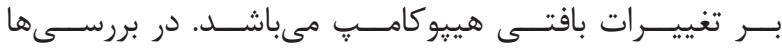

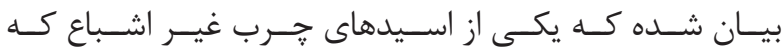

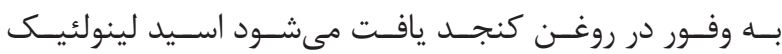

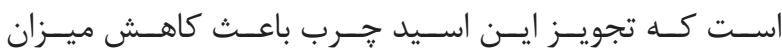

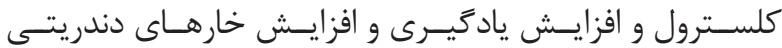

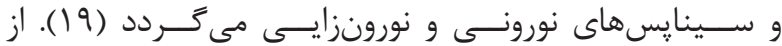

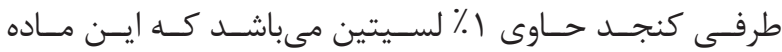

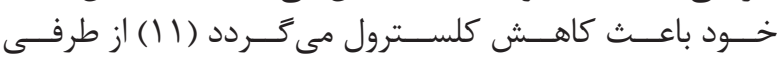

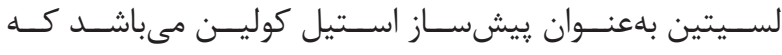

$$
\begin{aligned}
& \text { منابع }
\end{aligned}
$$

$\mathrm{J}$, et al. Estrogens exert a rapid apoptotic action in anterior pituitary cells. Am J Physiol Endocrinol Metab. 2009; 296(4): E664-E671.

8. Pawluski JL, Brummelte S, Barha CK, Crozier TM, Galea LA. Effects of steroid hormones on neurogenesis in the hippocampus of the adult female rodent during the estrous cycle, pregnancy, lactation and aging. Front Neuroendocrinol. 2009; 30(3): 343-57.

9. Balu DT, Lucki I. Adult hippocampal neurogenesis: regulation, functional implications, and contribution to disease pathology. Neurosci Biobehav Rev. 2009; 33(3): $232-52$.

10. Van Wyk B-E, Wink M. Medicinal plants of the world: CABI; 2017.

11. Lee C-L, Liao H-L, Lee W-C, Hsu C-K, Hsueh F-C, Pan J-Q, et al. Standards and labeling of milk fat and spread products in different countries. J Food Drug Anal. 2018; 26(2): 469-80.

12. Nakamura Y, Li-Beisson Y. Lipids in plant and algae development. Springer; 2016.

13. Sandler SI. Chemical, biochemical, and engineering thermodynamics. John Wiley \& Sons; 2017.

14. Che C-T. Review of duke's handbook of medicinal plants of the bible. ACS Publications; 2018. 
15. Peterson AM, Kelly WN. Managing pharmacy practice: principles, strategies, and systems. CRC Press; 2016.

16. Ahmad S, Khan MB, Hoda MN, Bhatia K, Haque R, Fazili IS, et al. Neuroprotective effect of sesame seed oil in 6-hydroxydopamine induced neurotoxicity in mice model: cellular, biochemical and neurochemical evidence. Neurochem Res. 2012; 37(3): 516-26.

17. Bendich A, Brock P. Rationale for the introduction of long chain polyunsaturated fatty acids and for concomitant increase in the level of vitamin $\mathrm{E}$ in infant formulas. Int J Vitam Nutr Res. 1997; 67(4): 213-31.

18. Frye CA, Rhodes ME, Dudek B. Estradiol to aged female or male mice improves learning in inhibitory avoidance and water maze tasks. Brain Res. 2005; 1036(0): 101-8.

19. Pike CJ, Nguyen T-VV, Ramsden M, Yao M, Murphy MP, Rosario ER. Androgen cell signaling pathways involved in neuroprotective actions. Horm Behav. 2008; 53(5): 693-705.

20. Spritzer MD, Daviau ED, Coneeny MK, Engelman SM, Prince WT, Rodriguez-Wisdom KN. Effects of testosterone on spatial learning and memory in adult male rats. Horm Behav. 2011; 59(4): 484-96.

21. Moffat SD, Zonderman AB, Metter EJ, Blackman MR, Harman SM, Resnick SM. Longitudinal assessment of serum free testosterone concentration predicts memory performance and cognitive status in elderly men. J Clin Endocrinol Metab. 2002; 87(11): 5001-7.

22. Pike CJ. Sex and the development of Alzheimer's disease. J Neurosci Res. 2017; 95(1-2): 671-80.

23. Kordower JH, Chen E-Y, Morrison JH. Longterm gonadal hormone treatment and endogenous neurogenesis in the dentate gyrus of the adult female monkey. Exp Neurol. 2010; 224(1): 252-7.

24. Sun H, Deng Q, Pan Y, He B, Ying H, Chen J, et al. Association between estrogen receptor 1 (ESR1) genetic variations and cancer risk: a meta-analysis. J Buon. 2015; 20(1): 296-308.

25. Korach KS, Couse JF, Curtis SW, Washburn TF, Lindzey J, Kimbro KS, et al. Estrogen receptor gene disruption: molecular characterization and experimental and clinical phenotypes. Recent Prog Horm Res. 1996; 51: $159-86$.

26. Laouafa S, Bairam A, Soliz J, Roussel D, Joseph V.
Estradiol receptor agonists $\alpha$ and $\beta$ protect against brain mitochondrial dysfunction in a model of sleep apnea. The Faseb Journal. 2017; 31(1): 6966.

27. Lau ES-W, Zhang Z, Qin M, Ge W. Knockout of zebrafish ovarian aromatase gene (cyp19a1a) by Talen and Crispr/Cas9 leads to all-male offspring due to failed ovarian differentiation. Sci Rep. 2016; 6: 37357. doi: $10.1038 / \operatorname{srep} 37357$.

28. Spencer JL, Waters EM, Romeo RD, Wood GE, Milner TA, McEwen BS. Uncovering the mechanisms of estrogen effects on hippocampal function. Frontiers Neuroendocrinology. 2008; 29(2): 219-37.

29. Kempermann G, Song H, Gage FH. Neurogenesis in the adult hippocampus. Cold Spring Harb Perspect Biol 2015; 7(9): a018812.

30. Brock O, Keller M, Veyrac A, Douhard Q, Bakker J. Short term treatment with estradiol decreases the rate of newly generated cells in the subventricular zone and main olfactory bulb of adult female mice. Neuroscience. 2010; 166(2): 368-76.

31. Daubner SC, Le T, Wang S. Tyrosine hydroxylase and regulation of dopamine synthesis. Arch Biochem Biophys. 2011; 508(1): 1-12.

32. Galea LA. Gonadal hormone modulation of neurogenesis in the dentate gyrus of adult male and female rodents. Brain Res Rev. 2008; 57(2): 332-41.

33. Fester L, Ribeiro-Gouveia V, Prange-Kiel J, Von Schassen C, Böttner M, Jarry H, et al. Proliferation and apoptosis of hippocampal granule cells require local oestrogen synthesis. J Neurochem. 2006; 97(4): 1136-44.

34. Ormerod B, Galea L. Reproductive status influences cell proliferation and cell survival in the dentate gyrus of adult female meadow voles: a possible regulatory role for estradiol. Neuroscience. 2001; 102(2): 369-79.

35. Liu F, Liao F, Li W, Han Y, Liao D. Progesterone alters Nogo-A, GFAP and GAP-43 expression in a rat model of traumatic brain injury. Mol Med Rep. 2014; 9(4): $1225-31$.

36. Bowers JM, Waddell J, McCarthy MM. A developmental sex difference in hippocampal neurogenesis is mediated by endogenous oestradiol. Biol Sex Differ. 2010; 1(1): 8. doi: 10.1186/2042-6410-1-8.

37. Wnuk A, Korol DL, Erickson KI. Estrogens, hormone therapy, and hippocampal volume in postmenopausal women. Maturitas. 2012; 73(3): 186-90. 